\title{
SPACE REGULARITY MANIFESTATION OF THE TEMPORAL VARIATION OF SEISMIC PARAMETERS: POSSIBILITY FOR THE STRONG SEISMIC ACTIVITY ASSESSMENT
}

\author{
Popandopoulos George ${ }^{1}$ and Baskoutas $\mathbf{I}^{2}$ \\ ${ }^{1}$ Earthquake Planning and Protection Organization, Seismotect. Div., Xanthou32, 15451 Athens. gpa- \\ padopoulos@oasp.gr \\ ${ }^{2}$ Geodynamic Institute, National Observatory of Athens, P.O. Box 2004811810 Athens, \\ i.basko@.gein.noa.gr
}

\begin{abstract}
In the present work the detailed analysis of the space-time variation, of the seismic energy released and b-value was performed, in order to study the space regularity manifestation of the temporal variation of seismic parameters, to test the reliability of the results and to compare the obtained temporal profiles in relation to the strong earthquake activity.

The study was carried out in the subduction zone along the western part of the Hellenic trench arc system. The earthquakes data, witch occurs in the five adjacent local areas in the period 1980-2007 were used.

The reliability of the results is tested positively for "internal" dubiety, against independent seismic data sets from adjacent local areas, being in common the processing method, and the properties of seismic catalogue.

It was found that in the majority of the cases (23 of 32) the significant temporal variation changes, considered as anomalies, can be related to the preparation process of the strong earthquakes $M s>5.7$, acting as intermediate term precursors. Based on these findings the quality index of the successful intermediate term earthquake predictions reach up to $71.9 \%$.

It is observed that the temporal variation of the seismic energy released anomalies were time shifted in respect to the central areas, toward to $N-N E$ and $S$-SE direction. Moreover it is found that the strong earthquakes occurrence also shows immigration, in respect to the central areas, along the concatenation of the adjacent local areas. These two observations may reveal the formation of a tectonic wave, in the broader area south of Zakynthos Island, Its velocity was estimated to be as 100 to $150 \mathrm{~km} /$ year.
\end{abstract}

Key words: seismicity parameters, temporal variation analysis, b-value, seismic energy, Greece.

\section{Introduction}

Seismicity parameters and their time and space analysis is a very common approach (Habermann and Wyss, 1984; Papadopoulos and Voidomatis, 1987; Bowman et al., 1998; Bowman and King, 2001; Bowman and Sammis, 2004; Papazachos, 2000; Wiemer, 2001; Papadopoulos et al., 2004), to investigate geodynamic regime in seismic active regions. Significant changes of the seismicity rate have been reported in several areas of the world (Wiemer and Wyss, 2002; Enescu and Ito, 2003; 
Baskoutas et al., 2007). In many cases temporal changes of the seismicity parameters, can be correlated to strong earthquake occurrence and they may consider as indicators of fore-coming strong earthquakes (Wyss and Baer, 1981; Gao and Gao, 2002; Zavyalov, 2002, Enescu and Ito, 2003, Monterosso, 2003; Papadopoulos and Baskoutas, 2006).

In this work, the temporal variation of the seismic parameters was examined, in order to reveal their space regularity in the western part of the Hellenic trench Arc system. This region is characterized for its high seismic activity in the Greek territory and the frequent occurrence of large earthquakes also. Moreover the reliability of the methodology, using independent sets of seismic data is tested. The presence of the subduction front between African and Euro-Asiatic tectonic plates also stimulates further interest to interpret the obtained results. Finally, given that the temporal changes of the seismicity parameters can be correlated to strong earthquake occurrence, here it is also examined the possibility to assess the results for intermediate term earthquake predictions in the area.

\section{Method and analysis}

The quantity $\log E 2 / 3$ and the parameter b-value have been obtained by the means of the Fast Big Earthquakes Estimation (hereafter FastBEE) algorithm and the respective analysis tool, develop and proposed by Papadopoulos and Baskoutas, (2003, 2009). In the FastBEE algorithm b-value were obtained by the maximum likelihood estimation method (Gusev, 1976; Van Wormer et al., 1976) using relationship proposed by Zavyalov and Sobolev, 1980, as follow:

where $\mathrm{N}_{\Sigma}$ is the number of earthquakes in the examined time window; $\mathrm{N}$ is the number of earthquakes in the magnitude range $M_{\text {min }}+n \Delta M ; n=0,1,2,3,4 \ldots$ is the weighting factor, $\Delta M$ is the unit of the magnitude increment equal to 0.20 and $\sigma_{\mathrm{b}}$ is the standard deviation of $b$-value determination.

Standard errors of $b$-value were calculated by the relationship:

The seismic energy released, in the form $\log \mathrm{E}^{2 / 3}$, is obtained by the means of the relationship:

where energy $\mathrm{E}$ is derived using the relationship, $\mathrm{E}=10^{1.5 \mathrm{Ms}+4.7}$, proposed by Papazachos and Papazachos (2000a) for Greek territory. In these estimates standard error is calculated by relationship: $\sigma_{\log \mathrm{E}}=0,4343 / \sigma_{\mathrm{E}}$

The time series of the seismic parameters were calculated applying a smoothing time window of 13 months, with one-month step. The current average value of parameters was assigned to the end of the smoothing window. Then obtained time series were then filtered with a triangular form filter. Length of the applied time window is defined as 13 months. The applied filter allows passing the periods equal or greater of the half filter width (Jenkins and Watts, 1968). Definition of the filter length 


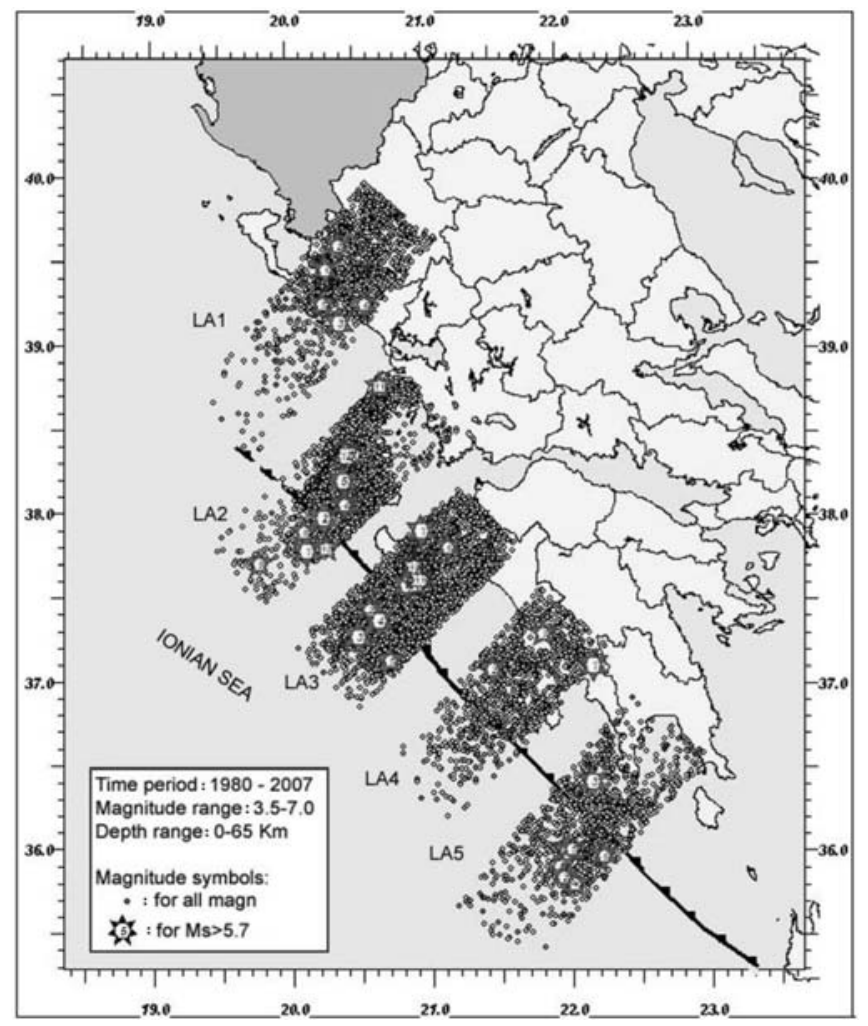

Fig. 1: Seismic epicentres map of the individual local areas. Size of the events is unique for the better spatial representation of the seismicity.

defined as long as 13 months makes the fluctuations with wave periods more than 6 months more evident. Filtered time series are displayed, as bold curves, superposed to the smoothed thinner one. Additionally chronologically numbered arrows have also marked the strong earthquakes origin time, within the examined time period, perpendicular to the time axis (see Figs 2 and 3).

\section{Data}

To reveal the spatial regularity of the seismic parameters temporal variation and to test the objectivity of the FastBEE analysis tool, six adjacent local areas (hereafter LA_1 ... LA_5) were defined. Their size is about 200x60 km each, with the major axis drafted perpendicular to the subduction front of the western part of the Hellenic Trench Arc system. Figure 1, shows the seismic epicenters maps of all 5 local zones. This region was chosen because for its high seismic activity, which provides enough data for the statistical assessment of the results and because of its geodynamic characteristics. The seismic data from each local area constitute "statistical independent samples", in order to test the reliability of the methodology.

The seismic data were taken from the catalog of the Geodynamic Institute of National Observatory of Athens in the period 1980 to 2007. In this period the catalogue is quasi uniform for magnitude of completeness 3.5 after 1990 and 4.0 in the period 1980 to 1990 at the local areas LA_1 in the northern part and LA_4 and LA_5, at the southern part. Table 1 shows the total number of earthquakes, for each local area, with Ms $>3.5$, which were used in the present study. Table 2 shows the list of all strong earthquakes with $\mathrm{M}>5.7$ which occurred in each local area and displayed in the respective time series output plots. 

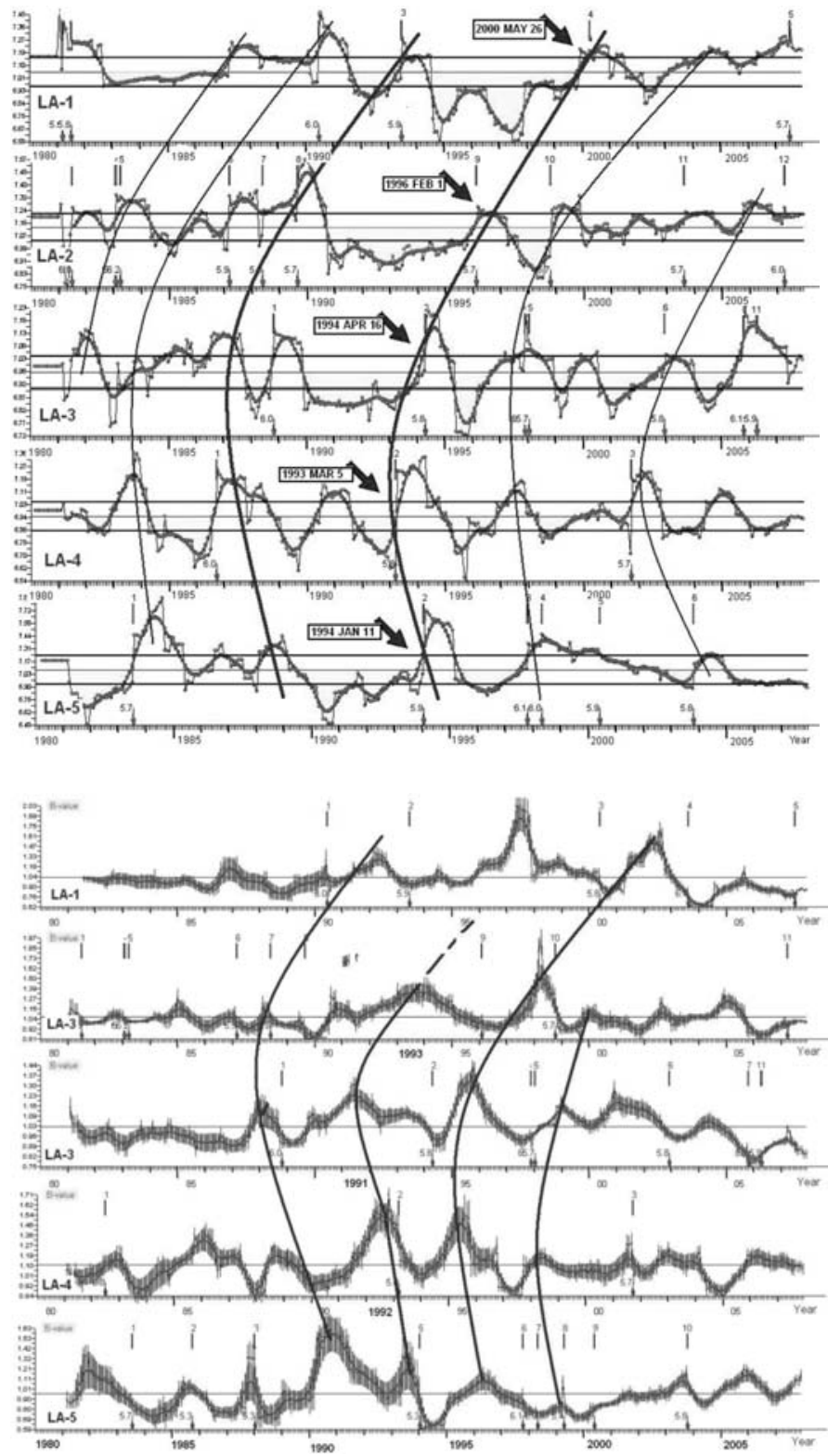

Fig. 2: Temporal variation plots of seismic energy released in adjacent seismogenic local areas in the Ionian Sea region. Solid and dashed lines connect the picks of the anomalies in the seismic energy time series (discussed in detailed in the text). Numbered arrows perpendicular to the time axis shows the origin time of strong earthquakes in each local area.

Fig. 3: Temporal variation plots of b-value obtained in adjacent seismogenic areas in the western part of the Hellenic arc. Thinner numbered arrows perpendicular to the time axis shows the origin time of strong earthquakes in each local area.

Table 1. Number of earthquakes used in this study for each local area.

\begin{tabular}{|c|c|}
\hline Local Areas & Date Number of Earthquakes \\
\hline LA_1 & 1627 \\
\hline LA_2 & 2731 \\
\hline LA_3 & 4707 \\
\hline LA_4 & 1195 \\
\hline LA_5 & 1954 \\
\hline
\end{tabular}


Table 2. List of the strong earthquakes at each local area.

\begin{tabular}{|c|c|c|c|c|c|c|}
\hline & Date & Or. Time & Lat & Lon & Depth & Magn \\
\hline \multirow[t]{3}{*}{ LA_1 } & 1981 MAR 10 & 151618.0 & 39.30 & 20.80 & 0 & 5.8 \\
\hline & 1990 JUN 16 & 021620.4 & 39.13 & 20.38 & 38 & 6.0 \\
\hline & 1993 JUN 13 & 232640.0 & 39.25 & 20.57 & 5 & 5.9 \\
\hline \multirow[t]{2}{*}{$*$} & 2000 MAY 26 & 012822.0 & 38.91 & 20.58 & 5 & 5.8 \\
\hline & 2007 JUN 29 & 180911.2 & 39.25 & 20.26 & 19 & 5.7 \\
\hline \multirow[t]{9}{*}{ LA_2 } & 1981 JUN 24 & 184126.0 & 37.80 & 20.00 & 0 & 5.7 \\
\hline & 1981 JUN 28 & 172021.0 & 37.90 & 20.10 & 0 & 6.0 \\
\hline & 1983 JAN 17 & 124130.9 & 37.97 & 20.25 & 9 & 6.7 \\
\hline & 1983 JAN 19 & 000215.5 & 38.05 & 20.41 & 6 & 6.0 \\
\hline & 1983 JAN 31 & 1527.6 & 38.05 & 20.41 & 2 & 5.8 \\
\hline & 1983 MAR 23 & 23517.6 & 38.19 & 20.40 & 10 & 6.2 \\
\hline & 1987 FEB 27 & 233454.1 & 38.37 & 20.42 & 1 & 5.9 \\
\hline & 1988 MAY 18 & 051742.7 & 38.35 & 20.47 & 1 & 5.8 \\
\hline & 1989 AUG 24 & 021313.4 & 37.89 & 20.11 & 1 & 5.7 \\
\hline \multirow[t]{3}{*}{$*$} & 1996 FEB 1 & 175756.5 & 37.72 & 19.85 & 1 & 5.7 \\
\hline & 1998 OCT 8 & 035017.1 & 37.79 & 20.27 & 5 & 5.7 \\
\hline & 2007 MAR 25 & 135758.2 & 38.34 & 20.42 & 15 & 6.0 \\
\hline LA_3 & 1988 OCT 16 & 12345.4 & 37.90 & 20.96 & 4 & 6.0 \\
\hline \multirow[t]{10}{*}{$*$} & 1994 APR 16 & 230936.4 & 37.43 & 20.58 & 30 & 5.8 \\
\hline & 1997 NOV 18 & 130736.9 & 37.26 & 20.49 & 5 & 6.6 \\
\hline & 1997 NOV 18 & 131348.3 & 37.36 & 20.65 & 5 & 6.1 \\
\hline & 1998 JAN 10 & 192154.3 & 37.12 & 20.73 & 5 & 5.7 \\
\hline & 2002 DEC 2 & 045856.4 & 37.80 & 21.15 & 17 & 5.8 \\
\hline & 2005 OCT 18 & 152559.5 & 37.58 & 20.86 & 22 & 6.1 \\
\hline & 2006 APR 4 & 22053.3 & 37.58 & 20.93 & 18 & 5.7 \\
\hline & 2006 APR 11 & 000241.5 & 37.64 & 20.92 & 18 & 5.7 \\
\hline & 2006 APR 11 & 172928.4 & 37.68 & 20.91 & 18 & 5.9 \\
\hline & 2006 APR 12 & 16521.2 & 37.61 & 20.95 & 19 & 5.9 \\
\hline \multirow[t]{3}{*}{ LA_4 } & 1986 SEP 13 & 172433.8 & 37.10 & 22.19 & 1 & 6.0 \\
\hline & 1993 MAR 5 & 06556.4 & 37.07 & 21.46 & 1 & 5.8 \\
\hline & 2001 SEP 16 & 020048.5 & 37.29 & 21.83 & 5 & 5.7 \\
\hline LA_5 & 1983 JUL 14 & 025421.6 & 35.80 & 22.03 & 18 & 5.7 \\
\hline \multirow[t]{5}{*}{$*$} & 1994 JAN 11 & 072253.3 & 35.84 & 21.95 & 40 & 5.9 \\
\hline & 1997 OCT 13 & 133939.2 & 36.41 & 22.18 & 6 & 6.1 \\
\hline & 1998 APR 29 & 033037.1 & 35.99 & 21.98 & 5 & 6.0 \\
\hline & 2000 MAY 24 & 054037.5 & 36.00 & 22.01 & 5 & 5.9 \\
\hline & 2003 OCT 17 & 12578.7 & 35.96 & 22.25 & 37 & 5.8 \\
\hline
\end{tabular}

*Bold typed lines shows the sequence of the events correlated with the main seismic energy anomalies reported as an example in the main text. In Fig. 2 they appear as solid arrows, which indicate their origin time. 


\section{Results}

Figures 2 and 3 , shows the time series of the temporal variation plots of seismic energy released and b-value plots respectively, in adjacent seismogenic local areas in the Ionian Sea region.

In both figures the origin time of the main strong earthquakes Ms>5.7 are shown with red arrows vertical to the time axis at each local areas. Solid curved dashed lines connect the picks of the sharp changes of the seismic energy and b-value time series respectively. In figure 2 the labelled (with the date of earthquake origin time) oblique arrows shows the spatio temporal shifting of sharp changes of the along the sequence of all local areas.

Table 3 shows the catalogue seismic parameters of all 32 strong earthquakes in the examined time period at each local areas. In both figures same phases of the temporal variation estimates fluctuations, can be considered as anomalies in respect to their relative mean values, (line parallel to time axis). Specifically, the parameter $\log \left(\mathrm{E}^{2 / 3}\right)$ of the seismic energy released passes a relative minimum (valley shape curve), before the strong earthquake occurrence and then increases as seismic activity develops further to the aftershock activity. In the opposite, b-value shows a clear decreasing phase prior to the occurrence of a strong earthquake, after having past a relative maximum. It is observed, that in the majority of the cases, there is a correlation between temporal variation anomalies with strong earthquakes of at each local area. In some other case instead of singular strong earthquake, this correlation is related to a cluster of strong earthquakes. An example of this case is the strong seismic activity occurred in the period 4 to 12 of April of 2006, at the local area 3 (LA_3 in Figure 2). Here is to note that the duration of anomalies observed before the strong earthquakes is about 1 to 4 years. Their observed size and duration seems to be not proportional the magnitude of the associated strong earthquake. Detail analysis of this relation is beyond to the scope of this work and is going to examine in future study.

To evaluate the correlation of the seismic energy released anomalies with the strong earthquakes, all the cases from all local areas were examined, by the means of the prediction quality index estimation proposed by Kasahara (1981):

$$
\mathrm{p}=\mathrm{m} / \mathrm{n}
$$

Where $p$ is the probability of occurrence of the strong earthquake related to an anomaly presence, $m$ is the number of successful prediction and $n$ is the total number of the strong earthquakes examined. Table 3 shows the number of the strong earthquakes, the respective successful correlation with seismic energy anomalies and the failed cases at each local area. There were six cases of anomalies, which are not accompanied by an earthquake and 8 cases of strong earthquakes, which were uncorrelated.

Table 3. Number of the successful and failed cases in each local area

\begin{tabular}{|c|c|c|c|c|}
\hline Local area & Number of EQs & Successful cases & $\begin{array}{c}\text { EQ with no } \\
\text { anomaly }\end{array}$ & $\begin{array}{c}\text { Anomaly } \\
\text { With no EQ }\end{array}$ \\
\hline LA_1 & 5 & 4 & 1 & 1 \\
\hline LA_2 & 9 & 6 & 2 & 1 \\
\hline LA_3 & 8 & 5 & 2 & 1 \\
\hline LA_4 & 3 & 3 & - & 3 \\
\hline LA_5 & 7 & 5 & 3 & 0 \\
\hline Sum & 32 & 23 & 8 & 6 \\
\hline
\end{tabular}




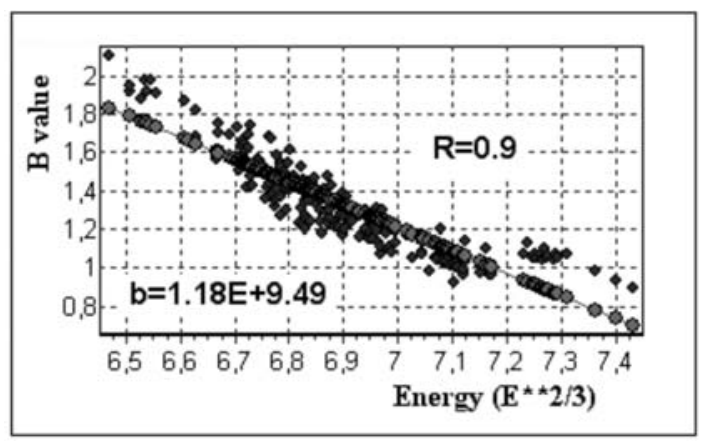

Fig. 4: Seismic parameters b-value and $\log E^{2 / 3}$ temporal variation correlation, for the local area 4.

It was found that in the majority of the cases, 23 of 32 the correlation is strong. Thus temporal variation anomalies of the seismic energy released can be considered as intermediate term earthquake precursors. The quality index of the successful cases is then calculated as:

$$
\mathrm{P}=23 * 100 / 32=71.9 \%
$$

Comparison of the parameters $\log \mathrm{E}^{2 / 3}$ and b-value curves (Fig. 2 and 3) shows antiphase of their temporary variations fluctuations, namely the temporary decrease phases of parameter $\log \mathrm{E}^{2 / 3} \mathrm{corre}$ spond to an increase one of the b-value. The correlation analysis between time series of these parameters shows a correlation coefficient of 0,9 . Fig. 4 shows, as an example, the correlation of parameters $\log \mathrm{E}^{2 / 3}$ and $b$-value, for the local area 4 . The observed strong correlation factor between two independent parameters proves also the objectivity of the methodology to obtain seismic parameters temporal variation.

The careful visual inspection of Fig. 2 shows that the seismic energy released reveal anomalies (fulfilled with yellow colour) can be correlated, across the sequence of the individual graphs. The key point to follow these correlations come from the observation of the similar shape and size anomalies formed first at LA_2 and LA_3 in the period 1990 to 1995. Almost similar shape and size anomalies, except LA_4, can be distinguished to the rest areas, LA1 toward to north and LA4, LA5 to south. This sequence of correlated anomalies is denoted by the two thicker blue solid lines of Fig. 2 .

Continuing the inspection of Fig. 2, next to the major sequence of the anomalies during 1990-1995, consecutive minor size anomalies at neighbour local areas can be identified. Albeit the smaller size of the anomalies and the weaker correlation, this last still can be evident. Moreover an immigration of the strong earthquakes can be observed, starting from the central areas to the adjacent local areas, toward NE and SE, which also can be and correlated. For instance, in figure 2, the case of the stronger correlation of the Ms = 5.8 strong earthquake of April 16, 1994 occurred in LA_3, can be associated with the anomaly, starting in 1990. Similar anomalies shifting and strong earthquakes immigration can be observed to the NE direction, associated to the 1993, March 5, in LA4 and 1994 January 11, in LA5, earthquakes respectively. Again similar anomalies associated to the Ms=5.7, 1996, February 1, in LA2 and to the Ms=5.8, 2000, May 26 in the LA1 earthquakes, are spreading toward SE direction.

On the basis of previously mentioned observations it is possible to talk about a propagation of the anomalies, which shows a clear time shifting and space migration in either side of the middle local areas, toward to north and south. This observation is clearer for the seismic energy plots than those of b-value. From this observation we may conclude that strong earthquakes occurrence can be ex- 
pected with 1 or 2 years delay, in the neighbour adjacent local areas, next to LA_4 (being a reference point), toward north and south. Weak correlation on temporal variation of $b$-value anomalies (figure 3) may be related to the seismic catalogue incompleteness, which seems to influence the quality of the b-value results, at least at the northern and southern local area.

\section{Discussion-Conclusions}

In this work were examined the space regularity of the temporal variation of the seismicity focusing on seismic energy released and the b-value, under the assumption that its temporal changes are closely related to the seismic activity of the observed region. Moreover the reliability of the analysis method was tested, since "internal" estimates objectivity of any procedure is a source of dubiety, (Steyerberg et al., 2003)

In this work the reliability of the FastBEE tool analysis to compute seismicity parameters temporal variation was tested, taking seismic data sets from adjacent local areas, so that they can considered "statistical independent samples". Thus obtained temporal variation estimates, being in common the processing method and definition of all analysis parameters as well as the earthquake catalogue properties, was tested positively.

It is observed that in many cases, sharp fluctuation anomalies, which can be considered as anomalies, can be correlated with strong earthquakes seismic activity. Precisely their origin time lies within the increasing phase of seismic energy and the decreasing one of b-value, after have passed a relative minimum and maximum respectively. Thus temporal variation anomalies of the seismic energy released can be considered as intermediate term earthquake precursors. Nevertheless, the size and the duration of the anomalies observed seem to be not proportional to the magnitude of the associated strong earthquake. Some times despite of the anomaly presence there is no earthquake but the anomaly can be correlated to a cluster of smaller size earthquakes. In few other cases there are earthquakes without the presence of an anomaly. The quantitative assessment of the successful intermediate term earthquake predictions, within the limits of the examined local areas and time period was found to be approximately $72 \%$.

It is found a clear temporal shifting of the temporal variation fluctuations toward to N-NE and S-SE directions. At the same time it is also observed a spatio-temporal immigration of the strong earthquakes toward to northern and southern regions. In both cases the shifting is considered in respect to the central local areas 3 and 4.

From the combination of these two observations and taking in to account the geodynamic regime in he region, we may assume the formation of a tectonic wave in the broader area south of Zakynthos Island, which propagates toward to E-NE and E-SE. Knowing the distances of the geometrical centres of consecutive local areas and the mean time sifting of the energy anomalies, then we can infer that the propagation velocity of the detected "tectonic wave" can be estimated to be as 100-150 $\mathrm{km} / \mathrm{yr}$.

One possible hypothesis of the formation of the observed "tectonic" wave can be based on the geodynamic regime dominated the examined region. Entire region is characterized by the presence of the subduction zone as a result of the convergence between Eurasian and African tectonic plates. It is possible to assume that the presence of the constant regional tectonic stress acting along the western part of Greek arc system, cause the rock breaking and released first the energy in the central areas LA_3 and LA_4 and then propagates further to southern and to northern directions. One explanation, why this effect take place in these regions, may be the smaller interior rock friction in this 
areas, in respect to the adjacent one. According to the findings of this work local areas LA_3 and LA_4 may be a key point of the collision between the two lithospheric plates, in the WS part of the Greek arc system. Certainly, such plausible hypothesis however it explains the observed shifting of anomalies of the seismic parameters temporary variations and need further investigation.

As a conclusion can state that the reliability of the analysis to obtained temporal variation of the seismicity was tested positively. The study of its space regularity, revealed the presence of a "tectonic" wave. The high probability of successful intermediate term earthquake prediction was also proved. We hope that the FastBEE algorithm will be useful for the study and continuous monitoring of the seismicity temporal variation. It is also believed that these results can add information and contribute in the seismic hazard assessment in highly seismogenic regions.

\section{References}

Baskoutas I. Papadopoulos G. A. Karakostas V. and Papadimitriou E. 2007. Recent 2005-2006 strong seismic activity in Greece under the aspect of seismicity parameters temporal variation. Bulletin of Geological Society of Greece. XXX/3, 1055-1062p.

Baskoutas I. Papadopoulos George and G. Panopoulou, 2004. Long temporal variation of seismic parameter for seismic pattern identification in Greece.10th International Congress of GSG. Thessaloniki, April 2004

Bowman, D. D., and G. C. P. King (2001), Accelerating seismicity and stress accumulation before large earthquakes, Geophys. Res. Lett., 28, 4039-4042.

Bowman, D. D., Ouillon, G., Sammis, C. G., Sornette, A., and Sornette, D. (1998). “An observational test of the critical earthquake concept". J. Geophys. Res., 103, pp 24359-24372.

Bowman, D., and C. G. Sammis (2004), Intermittent critical and the Gutenmberg-Richter distribution, Pure Appl. Geophys., 161. 1945-1956.

Earthquake catalogue. Geodynamic Institute of National Observatiry of Athens. (www.gei.noa.gr)

Enescu B. and Ito K. 2003. Values of b and p: their Variations and Relation to Physical Processes for Earthquakes in Japan. Annuals of Disas. Prev. Res. Inst., Kyoto Univ., No.46 B.

Gao A. and Gao S. S. 2002. Temporal variation of seismic b-values beneath NE Japan island arc. Geoph. Res. Letters, 29, 9.

Gusev A. A. 1976. Indicator earthquakes and prediction. In Seismicity and Deep Structure of Siberia and Far East, Nauka, Novosibirsk, 1976 (in Russian), 241247.

Habermann R. E. and Wyss M. 1984. Background Seismicity Rates and Precursory Seismic Quiescence: Imperial Valley, California, Bull. Seismol. Soc. Am. 74, 1743-1755p

Jenkins, G. M and Watts D. G. 1968. Spectral Analysis and its Applications (Holden-Day Publishing Co., New York.

Kasahara K. Earthquake mechanics. Canbridge earth sciences series . Univ. of Tokyo 1981

Monterroso Juarez, D. A. 2003. Statistical Seismology Studies in Central America, b-value, seismic hazard and seismic quiescence, Comprehensive Summaries of Uppsala Dissertations from the Faculty of Science and Technology, Acta Universitalis Upsaliensis, 897, 27 pp. Uppsala, ISBN 91-554-5761-4.

Papadopoulos George and Baskoutas I. 2006. Prognostic character of FastBEE analysis for seismic hazard assessment in Greece. 2nd International Workshop on Earthquake Prediction, Rion Patras June 26, 2006.

Papadopoulos George and Baskoutas I. 2009. New tool for the temporal variation analysis of seismic parameters. Nat. Hazards Earth Syst. Sci., 9, 859-864. (www.nat-hazards-earth-syst-sci.net/9/859/2009 
Papadopoulos George, I. Baskoutas and G. Stavrakakis, 2003. Tools for the Fast Estimation of Expected Big Earthquake in predefined seismic prone areas. 1th International Workshop on Earthquake Prediction. Athens, November 2003.

Papadopoulos Geras. and Voidomatis Ph. 1987. Evidence of periodic seismicity in the inner Aegean seismic area. Pageoph 125 4.613-628p.

Papazachos C. B. and Papazachos B. C. 2000. Accelerated preshock deformation of broad regions in the Aegean area. Pure and Appl. Geophys. 157, 163-168p.

Steyerberg E. W, Bleeker S. E. Moll H. A. Grobbee D. E. and. Moons K. G. 2003. Internal and external validation of predictive models: a simulation study of bias and precision in small samples. J. Clin. Epid. 56(5) 441-448p.

Van Wormer J. D. Gedney L. D. Davies J. N. Condal N. 1976. Vp/Vs and b-values: a test of the dilatancy model for earthquakes precursors. Geophys. Res. Lett. 2, 11, pp.514-516.

Wiemer, S., 2001. A software package to analyze seismicity: ZMAP. Seismological Research Letters 72, 373-382.

Wiemer S. 7 Wyss M. 2002. Spatial and temporal variability of the b-value in seismogenic volumes: An overview, Advances in Geophysics, 45, 259-302.

Wyss M. and Baer M (1981). Seismic quiescence in the western Hellenic arc may foreshadow large earthquakes. Nature, 289: 785-787p.

Zavialov A. D. and Sobolev G. A. 1980. Some regularities of seismic regime and earthquake prediction. Proc. $17^{\text {th }}$ Gen. Assembly of ESC. Budapest. 65-69.

Zavyalov A. D. 2002. Testing the MEE prediction algorithm in various seismically active regions in the 1985-2000 period: results and analysis. // Izvestiya. Physics of the solid Earth, 38, JVs 4 262-275p. 